\title{
CUERPO Y VERDAD EN EL JOVEN NIETZSCHE: APUNTES SOBRE LA GÉNESIS DE LA PROBLEMÁTICA GNOSEOLÓGICA EN SOBRE VERDAD Y MENTIRA EN SENTIDO EXTRAMORAL
}

\section{BODY AND TRUTH IN YOUNG NIETZSCHE: REMARKS ON THE GENESIS OF THE GNOSEOLOGIC PROBLEMATISATION IN ON TRUTH AND LIES IN A NONMORAL SENSE}

\author{
KILIAN LAVERNIA * \\ UNED
}

Resumen: La investigación reconstruye dos momentos formativos del joven Nietzsche que ilustran la continuidad de determinadas preocupaciones gnoseológicas que cristalizarán en el escrito Sobre verdad y mentira en sentido extramoral (1873). Por un lado, sus apuntes filosóficos de la época universitaria de Leipzig (1865-1868), en los que se articula ya un diálogo crítico con las teorías del conocimiento de Schopenhauer y Kant; por el otro, sus trabajos y lecturas preparatorios para los cursos de retórica impartidos en 1872/73. Frente al lugar común que caracteriza su obra de juventud en términos estrictamente románticos, el artículo propone una imagen más diferenciada de una atípica formación filosófica, cuya importancia radica en reevaluar algunas líneas

*Profesor Ayudante en el Departamento de Filosofía de la UNED. E-mail: klavernia@fsof. uned.es. Dirección: Facultad de Filosofía, Edificio de Humanidades, 2a planta (despacho 224), c/ Senda del Rey 7, 28040, Madrid. La redacción de este artículo, cuyo origen se remonta a una comunicación presentada en mayo de 2015 con ocasión del VII Congreso de la Sociedad Académica de Filosofía celebrado en Cádiz, ha sido posible gracias a una beca de investigación FPI (BES-2012-053694) financiada por el MINECO. 
de fuerza que no sólo dan unidad a determinadas temáticas de su obra juvenil, sino que enlazan también con preocupaciones centrales de su pensamiento de madurez, tales como la crítica a la metafísica, al lenguaje y a la ciencia, o las reflexiones sobre el cuerpo y la vida.

Palabras Clave: joven Nietzsche - gnoseología - lenguaje - verdad - cuerpo

Aвstract: This investigation explores two formative moments of young Nietzsche, that illustrate the continuity of certain gnoseologic concerns which lead to On Truth and Lies in a Nonmoral Sense (1873). On one hand, his philosophical notes of his university years in Leipzig (1865-1868), in which he already articulates a critical dialogue with the Kantian and Schopenhauerian theories of knowledge; on the other hand, his preparatory works and readings for his Rhetoric lectures in 1872/73. Unlike the common view that characterizes his juvenile work in strictly romantic terms, this article proposes a more differentiated image of a non-typical philosophical education, which is important not only because it reevaluates some major lines of his juvenile period, but also because it connects it to central concerns of his mature works, such as the critique of metaphysics, language and science, or his thinking on the body and life.

KEYwORDS: young Nietzsche - gnoseology - language - truth - body

\section{Introducción}

El siguiente artículo se propone explorar, en dos movimientos claramente definidos, el proceso de búsqueda, experimentación y conquista filosóficas en el joven Nietzsche con ocasión de la problemática gnoseológica que se articula en su escrito Sobre verdady mentira en sentido extramoral (1873). Como es sabido, este breve ensayo de juventud plantea la conocida tesis de la naturaleza tropológica del lenguaje, es decir, la tesis según la cual todo lenguaje no sería otra cosa que un largo y olvidado proceso inconsciente de metaforización que no estaría hecho para decir la verdad, para denotar una determinada realidad en sí presente a la conciencia humana, sino para connotar una relación específica con las cosas, mejor aún, una relación de naturaleza estética en la que habríamos olvidado la necesidad constitutiva de la mentira como condición de posibilidad de la vida misma. Su pasaje más conocido es, desde luego, uno de los más bellos de todo el opus nietzscheano: 
¿Qué es, pues, la verdad? Un ejército móvil de metáforas, metonimias, antropomorfismos en movimiento, en una palabra, una suma de relaciones humanas que han sido realzadas, extrapoladas, adornadas poética y retóricamente y que, tras un prolongado uso, a un pueblo le parecen fijas, canónicas, obligatorias: las verdades son ilusiones que se ha olvidado que lo son, metáforas que han quedado gastadas y sin fuerza sensible, monedas que han perdido su imagen y que ahora ya no se consideran como monedas, sino como metal (Nietzsche, 2011: 529-530).

Es sabido que algunas de las líneas interpretativas más decisivas durante el linguistic turn han mostrado con solvencia que el abordaje teórico de este texto pasa por una necesaria reevaluación de la dimensión retórica de la Sprachtheorie nietzscheana (Lacoue-Labarthe, 1971; Kofman, 1972; de Man, 1990), una dimensión que, además, debe ser estudiada siempre desde el trasfondo científico y filosófico de su época (Crawford, 1988; Meijers, 1988; Meijers/Stingelin, 1988; Borsche, 1994; Behler, 1994; Orsucci, 1994). Ahora bien, la importancia de este escrito con vistas al planteamiento de madurez no está lo bastante estudiada desde su temprano arraigo teórico en el joven Nietzsche, sobre todo desde su confrontación crítica con las teorías del conocimiento de Kant y Schopenhauer. O dicho con mayor precisión: desde su confrontación con algunas de las líneas de fuga gnoseológicas que su recepción en Alemania había priorizado a partir de la segunda mitad del siglo XIX, ya fuera vinculada a la configuración epistemológica del emergente neokantismo alemán, ya fuera condicionada por la irrupción epocal del darwinismo y las dificultades que su integración teórica planteaba a todas las parcelas científicas por igual, incluida la propia filosofía.

Por todo ello, el siguiente artículo se propone reconstruir dos de las paradas teóricas más importantes para entender la conquista filosófica que se expresa en Sobre verdad y mentira en sentido extramoral. Aun separados por el tiempo, la vinculación temática de las preocupaciones gnoseológicas de estos dos momentos formativos, lejos de ser subterránea o secreta, constituye uno de los caminos más fascinantes del pensar nietzscheano.

\section{Los años formativos en Leipzig - un sedimento capital}

La primera estación para entender la problemática gnoseológica que aquí nos ocupa se remonta a los años formativos en la Universidad de Leipzig, entre 
1865 y 1868. En esta época universitaria somos testigos de una serie de esfuerzos estrictamente filosóficos, esto es, asistimos a una dedicación intelectual cuya finalidad es complementar y enriquecer una philosophische Bildung que el rígido marco de la formación filológica jamás habría hecho posible. Estos materiales, titulados "Apuntes para un ensayo de Demócrito", "Sobre Schopenhauer" y "La teleología a partir de Kant” (Nietzsche, 2011: 241-320), son relativamente poco conocidos en el ámbito hispanohablante y, a la vista de su importancia, merecen una urgente revisión. Con todo, si quisiéramos encontrar una de las fuentes más importantes que impulsaron su confección, no me parecería desacertado remitir, junto al impulso ya conocido de Schopenhauer, a la lectura que hizo de la Historia del materialismo, publicada por Friedrich Albert Lange en 1866. Desde las tempranas intuiciones de Hans Vaihinger (1911), la innegable influencia de este libro no sólo ha sido estudiada con mucha solvencia en lo que respecta a su formación filosófica y científica (Salaquarda, 1977; Stack, 1983), sino incluso también con respecto a su propia formación filológica, como ha demostrado Porter (2000: 48-60), por tanto, la tarea que nos recae aquí consiste en explorar hasta qué punto las tres líneas maestras que presentaremos a continuación dependen, entre otras cosas, de la asimilación total o parcial de algunas de sus premisas teóricas.

\subsection{La inaccesibilidad de la cosa en sí}

La primera línea maestra nos obliga a lanzar una mirada más atenta a los apuntes reunidos bajo el título "Sobre Schopenhauer". En estos materiales, redactados entre finales de 1867 y principios de 1868 a sugerencia, de acuerdo con Crawford (1988: 95), de su amigo Paul Deussen, el joven Nietzsche somete un análisis crítico el núcleo de la filosofía teorética de Schopenhauer. Más concretamente, pone en tela de juicio el célebre "pensamiento único" según el cual el mundo sería el autoconocimiento de la voluntad, entendida como verdadera esencia de las cosas, como experiencia interna que no puede ser conocida científicamente -pues no está sometida ni a la causalidad ni a las formas trascendentales del espacio y del tiempo-, sino sólo intuida como incesante sucesión de un irrefrenable querer vivir. Para Nietzsche, ni la afirmación de la unidad de la voluntad ni su precedente kantiano en cuanto cosa en sí pueden dar por sí solos con la solución del enigma del universo, de ahí que el dictum goetheano "Ob nicht Natur sich doch ergründe?", tan estimado por Schopenhauer, tenga 
que replantearse, cuando menos, desde otro acceso epistemológico (Nietzsche, 2011: 293).

En efecto, siguiendo tanto la crítica de Rudolf $\mathrm{Haym}^{1}$ como, por otro lado, la interpretación de Friedrich Überweg que recogía el manual de Lange (1866: 468-475), el joven estudiante se hace eco de las mismas críticas que Lange había realizado en su exposición del sistema de Kant. El término Wille, que Schopenhauer hace valer como cosa en sí, no sólo es una palabra "mal acuñada y de una amplísima extensión" (Schwergemünztes, viel umschliessendes Wort), sino que está constituida por una serie de predicados inapropiados que hacen de ella, "por decirlo como Überweg", una mera "categoría oculta" (versteckte Kategorie):

Pero incluso si se concede a Schopenhauer el derecho de seguir a Kant por esta peligrosa senda [la senda de la cosa en sí], lo que sustituye a lo incognoscible, a la x kantiana, es la voluntad, concebida nada más que con ayuda de una intuición poética, en la medida en que las demostraciones lógicas aportadas no pueden satisfacernos ni a nosotros ni al propio Schopenhauer. [...] nos vemos obligados a oponernos a los predicados que Schopenhauer asigan a su concepto de voluntad, los cuales, para algo que por definición es impensable, son demasiado determinados y extraídos todos de su antítesis con el mundo de la representación (Nietzsche, 2011: 295).

Un pasaje clave de $E l$ mundo como voluntad y representación sobre el que se basa esta temprana posición escéptica del joven Nietzsche nos remite al parágrafo 22 del libro primero (Schopenhauer, 2004: 180). El problema es el siguiente: si la voluntad es, por un lado, absolutamente exterior a nuestra esfera de

\footnotetext{
${ }^{1}$ La influencia del ensayo de Haym titulado Arthur Schopenhauer, publicado en 1864 en los Preussische Jahrbücher, ha sido magistralmente analizada por Sandro Barbera (Barbera, 1995: 124-136). La crítica de Haym que aquí nos interesa remite a la clásica antinomia que se desprende del "doble conocimiento" que, de acuerdo con la metafísica de la voluntad schopenhaueriana, tendríamos simultáneamente de nuestro cuerpo. Haym señala que, al fundamentar el origen del intelecto indistintamente desde una concepción trascendental e inmanentista de la voluntad, la argumentación de Schopenhauer incurría en una suerte de círculo vicioso según el cual la voluntad producía las representaciones -por tanto, el conocimiento en la modalidad del mundo fenoménico- sólo a través de su individuación, pero ésta, a su vez, sólo era posible a través del espacio y el tiempo, por tanto a través de las formas de conocimiento. Por consiguiente, sentenciaba, "de acuerdo con este esquema no es la voluntad, sino, en sentido estricto, el intelecto el que produce el intelecto", contradicción que Haym retrotrae -como hará también Nietzsche- a la utilización acrítica de la noción polisémica de "voluntad" (1995: 130-131).
} 
conocimiento fenoménico, pero, por el otro, esta voluntad "si es que tiene que ser pensada objetivamente, [...] debe "tomar prestado el nombre y el concepto de un objeto, de algo dado en cierto modo objetivamente, por tanto de uno de sus fenómenos", ¿cómo conciliar entonces la incongruencia de que la única manera de conferir objetividad a algo que en última instancia condiciona y hace posibles los fenómenos sea justamente atribuyéndole negativamente "predicados como ropajes variopintos, tomados de un mundo que le es extraño, el mundo fenoménico" (Nietzsche, 2011: 296)? La solución nietzscheana bebe nuevamente de Lange, ya que afirma que este préstamo fenoménico, esta vestimenta impuesta a una "x inaprensible y totalmente opaca", revelaría que el aparente carácter trascendente de la unidad de la voluntad puede retrotraerse a aquellas funciones del entendimiento que están determinadas en todo momento por nuestra propia organización psico-fisiológica. Los atributos de dicha voluntad, concluirá, "están, sin excepción, indisolublemente ligados a nuestra organización, de modo que es sumamente dudoso que puedan tener la menor importancia fuera de la esfera del conocimiento" (Nietzsche, 2011: 246).

De este modo, el joven estudiante ratificaba las conclusiones que había expuesto dos años atrás a su amigo Carl von Gersdorff, con ocasión de su primera lectura de la Historia del materialismo. Esta reflexión en caliente complementa, a mi modo de ver, la idea principal de este subapartado: la refractariedad nietzscheana a la hora de aceptar acríticamente el lado dogmático de la filosofía schopenhaueriana es inseparable de una primera irrupción del sedimento explicativo de tipo fisiológico, en el cual las condiciones a priori de nuestro conocimiento son retrotraidas por primera vez a instancias estrictamente biológicas.

Aquí tenemos ante nosotros a un kantiano muy ilustrado y a un investigador de la naturaleza. Sus conclusiones se pueden resumir en las siguientes tres proposiciones:

1) el mundo de los sentidos es el producto de nuestro organismo;

2) nuestros órganos visibles (corporales), como todas las otras partes del mundo fenoménico, son sólo imágenes de un un objeto desconocido;

3) nuestro verdadero organismo no es, por lo tanto, tan desconocido, como las cosas reales exteriores. Tenemos siempre ante nosotros sólo el producto de ambos. 
Por consiguiente la verdadera esencia de las cosas, la cosa en sí, no sólo es para nosotros desconocida, sino que también el concepto de ésta no es ni más ni menos que el último producto de una oposición, de la cual no sabemos si tiene algún significado de nuestra experiencia (Nietzsche, 2005: 412).

Mediante la radicalización del carácter fisiológico de nuestro conocimiento, la propuesta schopenhaueriana consigue mejorarse, a mi modo de ver, en un aspecto crucial: la intuición del propio cuerpo, es decir, la intuición de nuestra propia corporalidad, sigue siendo la "llave" del mundo, sí, pero ya no puede ser entendida schopenhauerianamente como aquel lugar de contacto privilegiado entre voluntad y representación que se sustraería al esquema kantiano del yo cognoscente, sino como parte integrante de una máquina autopoiética que simboliza la vida.

\subsection{El carácter artístico de nuestra conceptualización filosófica - Begriffsdichtung o "poesía conceptual"}

El temprano rechazo de algunos aspectos centrales del sistema schopenhaueriano no implicaba, desde luego, una enmienda a su totalidad. De hecho, la segunda línea maestra que vertebra los años formativos en Leipzig nace desde la propia conciencia de encontrarse en esta incómoda y no menos paradójica situación. ¿Cómo conciliar las inconsecuencias de un sistema filosófico que se quiere crítico, con la admiración por el genio, con la ejemplaridad del filósofoartista, con el pathos que encarna el individuo Schopenhauer? O dicho de otro modo: ¿cómo salvaguardar el valor edificante de la filosofía, pese a la constatación de que todo conocimiento, toda empresa que acometa una interpretación de la estructura fundamental de la realidad, está sujeta a los límites infranqueables antes señalados y por tanto al carácter relativo del saber y la razón humanas?

Conviene recordar, en este sentido, que ya en aquellos años formativos de Leipzig la solución conciliadora adoptada por el joven Nietzsche consistirá en desplazar la filosofía hacia el terreno del arte. El término Begriffsdichtung o "poesía conceptual” es un magnífico hilo conductor extraído de su lectura de Lange, para quien la filosofía puede ser entendida como una especie de "arte", igual que el lenguaje científico, en la medida en que la producción conceptual constituye un fenómeno artístico, figuras de nuestra imaginación que revelan una incansable actividad artística que determina, a su vez, el sentido de todo lo real. La 
reevaluación de la dimensión estética del concepto y de la verdad de la poesía no implica, sin embargo, la mera degradación ontológica de los conceptos, sino la integración inconsciente de la función del arte en el mismo proceso cognoscitivo. De ahí que las proposiciones de la ciencia tengan igual cabida en este orden de cosas más allá de su verdad y su falsedad, más allá de su adecuación a la razón, ya que, como todas las proposiciones del mundo, forman parte integrante de aquel proceso creativo y libre que es la conceptualización humana. La esquematización y la abreviación son también arte, un modo de pensar mitológico, en el que mediante una fórmula abreviada se cree poseer la esencia de las cosas.

Por todo ello, la aparente ambigüedad de la posición nietzscheana se resuelve en una segunda conquista intelectual: toda interpretación filosófica de la realidad puede ser entendida como una obra de arte, como producto de la fantasía. En primavera de 1868, el joven estudiante parece ser plenamente consciente de esta conquista, cuyo sedimento conforma, a mi modo de ver, uno de los estratos fundamentales de su pensamiento de juventud:

El reino de la metafísica, y con él la provincia de la verdad "absoluta", han sido irremisiblemente desplazados dentro de una única categoría junto con la poesía y la religión. Quien quiera conocer algo, que se limite ahora a una relatividad consciente del saber - como por ejemplo todos los famosos investigadores de las ciencias naturales. Así pues, para algunos la metafísica pertenece a la esfera de las necesidades del alma, es esencialmente edificante; por otro lado es arte, o sea, que permite la poetización del concepto [Begriffsdichtung]; pero una cosa es cierta, la metafísica, sea como religión o como arte, no tiene nada que ver con lo que se llama "lo verdadero o el ente en si" (Nietzsche, 2005: 495).

La importancia de este pasaje radica no sólo en el hecho de saber limar las diferencias formales que parecen separar las ciencias naturales de la filosofía, ya que, en cuanto productos de la fantasía, creaciones inconscientes de la productividad humana, ambas compartirían el mismo camino de conformación epistemológica a través de la conceptualización de sus intuiciones. También consigue, al mismo tiempo, expresar con claridad la función liberadora que pueda asumir toda metafísica, toda vez que sea edificante, como para Nietzsche es, sin duda, la filosofía schopenhaueriana. Si la filosofía es arte, y el arte es libre, la filosofía debe emerger también como garante último de esta "relatividad consciente del saber", precisamente porque el filósofo genial es capaz de defender creativamente la posibilidad de pensar la libertad del mundo - de evitar su exclusión como 
fuerza espiritual de lo humano- frente a las pretensiones totalitarias de la ciencia moderna y del orden necesario determinista que está en la base de su concepción mecanicista.

\subsection{La teleología como construcción antropomórfica}

Gracias a los numerosos materiales de los que disponemos en la actualidad, sabemos que la seguridad que transmitía esta última reflexión del joven Nietzsche estaba directamente condicionada por una tercera línea de búsqueda y experimentación filosóficas en su último año universitario de Leipzig. En el horizonte de aquella importante carta de abril se escondía, en realidad, el ambicioso proyecto de una tesis doctoral sobre el concepto de lo orgánico a partir de Kant, materiales que nos han llegado bajo el título La teleología a partir de Kant (Nietzsche, 2011: 304-320).

Como ya mostró con agudeza Nancy (1973: 62-66), el interés por el lugar común de la teleología había brotado con total naturalidad del ensayo inacabado sobre Demócrito, redactado de forma intermitente entre verano de 1867 y primavera de $1868^{2}$. Nietzsche había quedado fascinado por la capacidad del filósofo de Abdera por reconducir todo el desarrollo del universo a un movimiento simple, puramente mecánico, sin necesidad de recurrir a la intervención divina. Pese a su trágico destino personal, su sistema representaba la formidable culminación de una visión científica de la naturaleza, porque creaba una imagen unificada y coherente del mundo empírico. Por todo ello, la marcada actitud antimetafísica y antiteleológica del materialismo democríteo indicaba al joven estudiante una estrategia filosófica frente a 1) la posibilidad efectiva, alentada ya por Lange, de defender una explicación mecanicista del mundo -esto es, de

\footnotetext{
2 Este ensayo estuvo concebido, en un primer momento, como una disertación estrictamente filológica que debía ser incorporada a una obra colectiva dedicada a su maestro Ritschl. Ahora bien, a principios de 1868 , la inesperada dirección filosófica que tomaba el ensayo había revelado al estudiante quién debía ser su verdadero destinatario, nadie menos, en efecto, que el propio Friedrich Lange: "Me he propuesto firmemente conocer a este hombre y quiero enviarle mi escrito sobre Demócrito como signo de mi agradecimiento" (Nietzsche, 2005: 486). En este sentido, compartimos de lleno la opinión de Porter (2000: 34) cuando señala la interpretación altamente positiva de Lange respecto del filósofo atomista como clave de bóveda para entender la fascinación del propio estudiante: "The incentive was doubtless Nietzsche's discovery of Friedrich Albert Lange's just-published History of Materialism (1866), in which Democritus is featured as a cornerstone of the Western philosophical tradition down to Kant an into the ninenteenth century".
} 
acuerdo con un orden necesario y matemático- compatible con la imprevisibilidad del puro azar; 2) la posibilidad de hacerlo desde un innegable impulso poético y ardor científico, desembocando no obstante en la defensa de su significación filosófica como ética de la liberación de los hombres.

Ahora, sin embargo, en primavera de 1868 , la línea de investigación del joven estudiante se radicalizaba en la medida en que, secundada por la rigurosa interpretación de Kuno Fischer sobre Kant ${ }^{3}$, abordaba uno de los lugares comunes más recurrentes del emergente neokantismo, sobre todo desde su inevitable confrontación con el naturalismo radical de Darwin y la posibilidad de entender la conformación del mundo natural como una suerte de afinalismo mecanicista.

Nietzsche aboga, en líneas generales, por una crítica radical a la finalidad de la naturaleza desde el intento de mostrarla como pura construcción antropomórfica. En cierto modo, su intento parece querer corregir la aproximación doble sobre el finalismo que Schopenhauer había realizado, en el parágrafo 28 del libro segundo de El mundo como voluntad y representación (Schopenhauer, 2004: 209-213). En efecto, mientras que en la exposición schopenhaueriana sobre la finalidad interna el joven Nietzsche parece coincidir en la idea de que "el finalismo de lo orgánico, la conformidad a leyes de lo inorgánico, son introducidos en la naturaleza por nuestro entendimiento", la aproximación desde la finalidad externa, es decir, desde la consideración de que "todas las partes de la naturaleza convergen unas con otras porque la voluntad es una sola" (Nietzsche, 2011:305) -y como tal ha de manifestarse, por tanto, en el acuerdo de la diversidad de los fenómenos-, es inconsecuente a la luz de la gran conquista antropológica que

${ }^{3}$ La dependencia del joven Nietzsche con respecto a Kuno Fischer, sobre todo con respecto a los volúmenes 3 y 4 de su Geschichte der neueren Philosophie (Fischer, 1860), dedicados íntegramente al sistema kantiano, nos revela dos circunstancias negativas que no quisiera dejar de subrayar: en primer lugar, las numerosas paráfrasis e interpolaciones de aquella obra nos conducen a la importante línea de discusión de si el joven estudiante había leído directamente a Kant más allá de la tercera Crítica (Nancy, 1973: 74-76; Stack, 1991: 30-38; Hill, 2003: 83-86). Es cierto que Broese (2005: 363-371) ha trabajado recientemente, a partir de apuntes juveniles no incorporados a la KGW I, algunos primeros contactos con Kant en Pforta y Bonn, no obstante son materiales muy puntuales y de lectura indirecta.

En segundo lugar, como consecuencia de lo anterior, la confrontación indirecta vía Lange y Fischer con el criticismo kantiano explicaría en parte el malentendido de Nietzsche a la hora de atribuir a Kant la idea de que la "finalidad objetiva", puramente formal, sería extensible como "finalidad externa". En realidad, Kant otorgó un estatuto paradójico a lo que él llamaba "finalidad objetiva" (KdU, $\$ 62)$, pensada explícitamente como imposibilidad de presentar ningún objeto de esta clase. Para esta confusión del joven Nietzsche, remitimos a las pertinentes reflexiones de Gentili (2010: 111-115). 
precisamente está en la base de su visión pesimista de la naturaleza humana. Pues, ¿cómo negar que su idea de la "terrible lucha de los individuos y las especies" impulsados ciegamente por su querer vivir, esto es, aquella brutal expresión de un deseo y anhelo de existir a cualquier precio, una fuerza que plasma el movimiento sin finalidad, incesante y afanoso de todo lo que vive, constituye uno de los mejores argumentos contra el finalismo?

Si en la naturaleza no dominan más que fuerzas mecánicas, los fenómenos que responden a un fin no son, por su parte, más que aparentes, su finalismo no es más que nuestra idea. Las fuerzas ciegas actúan sin intención, no pueden, por tanto, producir nada que responda a un fin (Nietzsche, 2011:311).

Por tanto, sugiere Nietzsche, si pensamos hasta el final el célebre dictum kantiano de que sólo se comprende perfectamente lo que puede hacer y realizar uno mismo con sus conceptos (Nietzsche, 2011:311), la hipótesis de Lange arriba presentada sobre la poetización del concepto y la dimensión eminentemente creativa y artística de nuestro columbarium conceptual gana un nuevo argumento a su favor. Es más, el que todas las construcciones de sentido puedan retrotraerse, en última instancia, a una suerte de dimensión estética e inconsciente, que postula la existencia de una pulsión poética inherente al ser humano, deberá incluir también, sin excepción alguna, a todos los sistemas científicos de la época moderna, empezando por el mecanicismo y el evolucionismo. Ninguna torre de marfil es más alta que otra:

Por eso no se puede comprender perfectamente más que lo matemático (por tanto, comprensión formal). En lo demás, se está ante lo desconocido. Para hacer frente a esto el hombre inventa conceptos, pero que no abarcan más que un determinado número de propiedades fenoménicas, sin alcanzar a la cosa misma. Conceptos de éstos son los de fuerza, materia, individuo, ley, organismo, átomos, causa final (Nietzsche, 2011: 313).

En otras palabras: si la imposibilidad de demostrar que la naturaleza actúa de acuerdo con unos fines nos ofrece, en realidad, un magnífico ejemplo para entender cómo toda teorización científica se fundamenta siempre sobre la base de una representación simbólica que sólo nosotros habilitamos creativa y productivamente mediante nuestra propia conceptualización; si, por otro lado, la hegemonía epistémica del modelo newtoniano, que penetra todas las ciencias naturales, reduce drásticamente -dado su reductivismo mecanicista y su metodología 
analítico-disociadora- la multiplicidad y la riqueza de los fenómenos y se limita sólo a la observación del comportamiento externo de los fenómenos y al establecimiento de relaciones cuantificables entre ellos; entonces, por todo ello, ¿̨no parece razonable exigir otra dirección epistemológica que evite la dicotomía entre una aceptación ciega de la azarosidad de la vida y la inmutabilidad que nuestro conocimiento exige de ella a fin de aprehenderla científicamente? ¿Modificar, por tanto, la dicotomía kantiana entre necesidad y libertad, y dejar paso a una nueva forma de coaligar espíritu y libertad?

La dirección epistemológica que sugieren las breves pinceladas de la inacabada tesis doctoral es fascinante, ya que nos obliga a reevaluar seriamente la propuesta científico-natural de J.W. Goethe, sobre todo aquella que se deriva de su Morfología de las plantas (Goethe, 1997). Más que Schopenhauer, será de nuevo Lange (1866: 406) el que ofrezca aquí el impulso adecuado para el joven estudiante, pues de su libro extrae la bella aproximación gnoseológica de Goethe con respecto al conocimiento de la naturaleza como no-sistema, como pluralidad sin orden ni desorden, como vida y sucesión desde un centro desconocido hacia un confín incognoscible: "Todo ser vivo, dice Goethe, no es un individuo, sino una pluralidad: incluso cuando se nos muestra como individuo sigue siendo una reunión de seres vivientes independientes" (Nietzsche, 2011: 308; Goethe, 1997: 7).

No se puede insistir lo suficiente en la importancia de esta línea de investigación: frente a la afirmación kantiana del organismo como unidad teleológica, en la que las distintas partes actúan unas sobre otras de acuerdo con un diseño previo, la negación del individuo como unidad no sólo implica la pluralidad intrínseca de las perspectivas ligadas a formas de vida infinitamente diversas, sino que obliga, además, a redefinir la categoría de vida como eterno movimiento de despliegue o expansión de lo uno hacia lo múltiple, y de repliegue hacia la unidad primordial, una unidad, por tanto, que debe ser comprendida a partir de las partes, pero reconduciendo al mismo tiempo las partes, de nuevo, a la unidad. Y ello es así, porque la naturaleza no es un conjunto de elementos aislados y particulares que puedan ser sometidos pasivamente por un omnipotente sujeto cognoscente, sino un todo que se expresa en sus partes y que contiene su estructura más propia en su dinámica, en su incesante devenir ${ }^{4}$. Por tanto,

4 Sobre este último punto, el imprescindible estudio introductorio de Sánchez Meca señala lo siguiente: "Toda estructura, comprendida a la vez como una manifestación esencial y fenoménica de la naturaleza, consiste en su procesualidad. Lo individual no es el resultado de un 
cuando se habla de conceptos finales y de causas finales queremos expresar, en realidad, la bella idea de que

un ser viviente configura una forma en la que quiere aparecer. En otras palabras, la causa final no nos permite explicar mejor la vida, sino solamente la forma.

Ahora bien, en todo viviente no captamos sino formas. Lo que eternamente deviene es la vida. La naturaleza de nuestro entendimiento nos permite captar formas; nuestro entendimiento no es lo bastante fino como para percibir la continua transformación: a lo que puede conocer, lo llama forma. En realidad, no puede haber forma, porque en cada punto hay una infinidad. [...] Un concepto semejante al de la forma es el concepto de individuo. Se llama así a los organismos en cuanto unidades, en cuanto centros de fines. Pero para nuestro entendimiento no hay más que unidades. Todo individuo comporta en sí mismo una infinidad de individuos vivientes (Nietzsche, 2011: 261)

Por consiguiente, la idea de la naturaleza como originaria productividad creadora, que propugna su autoformación en la medida en que da vida y forma a las cosas individuales, modifica la relación cognoscitiva del hombre con respecto a la naturaleza, porque exige, como condición de posibilidad, nuestra autocomprensión también como naturaleza. Es un extraño ejercicio de humildad frente al antropocentrismo de la visión científica moderna, al tiempo que reafirma la idea de una consideración estética de todas las formas existentes en la naturaleza

proceso de individuación que se produce a partir de una desvinculación progresiva de su integración en el todo. Cada ser singular contiene en sí la naturaleza y no de manera estática, sino como metamorfosis y movimiento de autoformación" (Goethe, 1997: XXXIII-XXXIV). Sobre la importancia de la comprensión goetheana de la naturaleza en el joven Nietzsche me remito a mi artículo "Texturas goetheanas en el joven Nietzsche: apuntes sobre las funciones del Fausto en El nacimiento de la tragedia" [En prensa].

${ }^{5}$ Es decir, frente a la idea de una naturaleza explicada a partir de las causas finales, la negativa goetheana a separar kantianamente idealidad y materialidad había optado por una profundización de la concepción spinozista de la naturaleza como unidad de materia y espíritu, si bien adaptando su horizonte a una comprensión dinámica de transformación o metamorfosis continuas de la materia en la forma, como fuerza inmanente a la forma (Gestalt). La concentración goetheana en la forma garantizaba la persistencia temporal de algo formado en un proceso natural infinito, salvaguardando así la posibilidad epistemológica de pensar la multiplicidad inherente a todos los fenómenos, la simultaneidad de sus fuerzas concurrentes y, en definitiva, la generación de toda unidad natural en el flujo incesante de la vida sensible. 
como unidades meramente ficticias, estabilizadas tan sólo por la acción de nuestra facultad cognoscitiva que las secciona en la continuidad del devenir.

\section{Basilea, 1872 - De la retórica a la verdad}

La segunda parada teórica de nuestra reconstrucción nos lleva a Basilea, a finales de septiembre de 1872. Tras un verano muy difícil, condicionado por el inesperado estallido de la polémica sobre El nacimiento de la tragedia impulsada por el joven Wilamowitz (Nietzsche, 2011: 897-916), Nietzsche se encuentra preparando una serie de materiales para un curso de retórica que tiene que impartir en el semestre de invierno, y en ello se topa, en la biblioteca de su Universidad (Crescenzi, 1994: 418), con el primer volumen del reciente libro Die Sprache als Kunst (El lenguaje como arte), una ambiciosa obra de Gustav Gerber que explora distintos temas de la filosofía del lenguaje, a caballo entre la ciencia del lenguaje y la filosofía ${ }^{6}$. No era la primera vez que la labor estrictamente académica le había conducido a un lugar común tan controvertido como el del lenguaje. Ya en su primer semestre en Basilea, con ocasión de unas lecciones sobre gramática latina, el recién llegado profesor se había atrevido con una pequeña disertación inaugural titulada "Sobre el origen del lenguaje", que jugaba con la idea de explicar el lenguaje como producto de nuestro instinto natural, afirmando con ello la naturaleza figurativa de las palabras y sugerir, en consecuencia, la tesis según la cual los procesos lingüísticos inconscientes serían condición de posibilidad del uso consciente de la conceptualidad y la abstracción. Es difícil imaginarse la cara de los ávidos estudiantes de filología clásica que habían exigido aquel curso tan técnico ${ }^{7}$. Al menos ese día, el joven profesor hizo de filósofo:

No queda, por tanto, sino considerar el lenguaje como fruto del instinto, como en las abejas o en las hormigas, etc. El instinto, sin embargo, no es el resultado de una reflexión consciente, no es la simple consecuencia de la organización corporal, no es el resultado de un mecanismo situado en el cerebro, no es el efecto de algo que le viene al espíritu de fuera, extrańo a su

${ }^{6}$ La influencia de Gerber ha sido sobradamente estudiada en las últimas décadas, sobresaliendo sobre todo los trabajos de Meijers (1988) y Crawford (1988).

7 En efecto, en una carta de noviembre de 1869 dirigida a Erwin Rohde podemos leer: "Estoy impartiendo este invierno -por requerimiento de los estudiantes- igramática latina! Homo sum - pero es algo demasiado inhumano y para mí es además malditamente alienum" (Nietzsche, 2007: 105). 
esencia, sino que es la obra más propia del individuo o de una colectividad, algo que surge del carácter. El instinto es incluso idéntico con el núcleo más íntimo de un ser. Éste es el problema propio de la filosofía, la infinita finalidad de los organismos y la falta de conciencia en su origen (Nietzsche, 2013: 809-810).

Es cierto que la idea era deudora de la fundamentación filosófica de lo inconsciente defendida por Schelling -y reactualizada, aquel mismo año, por la importante obra de Eduard von Hartmann La filosofía de lo inconsciente, que Nietzsche leyó con mucha atención (Gerratana, 1988: 400-402) ${ }^{8}$-, pero daba por supuestas algunas de las conclusiones de la época de Leipzig, como la discusión con Kant sobre la teleología o la idea de la naturaleza artística de nuestra producción conceptual. Ahora, sin embargo, tres años después, el libro de Gerber aparecía en un momento clave. Señalemos brevemente las ideas básicas que Nietzsche compartirá con este autor:

Primero: que el lenguaje es un producto artístico de la creatividad humana, una especie de arte inconsciente de metaforización animado por una "pulsión artística" (Kunsttrieb), la cual, más que el entendimiento o la razón, es la que lleva la estructuración intelectual del mundo; segundo: que las palabras son, desde el comienzo, tropos, figuras, metáforas, entendidas no como simples afecciones externas, como meros ornatos o adornos accidentales, sino como esencia misma del lenguaje'; tercero: que es imposible que el lenguaje pueda describir o traducir la realidad, por cuanto nunca nombra o expresa una realidad en sí con un significado referencial propio, sino que connota una determinada experiencia o vivencia que los creadores del lenguaje tuvieron como proyección de sus

\footnotetext{
8 De hecho, de forma significativa, la cita clave de Schelling con la que Nietzsche concluye "Sobre el origen del lenguaje" y que refuerza la idea de una teleología sin conciencia no es sino la misma con la que Hartmann empieza su capítulo "Lo inconsciente en la formación del lenguaje" (Hartmann, 1869: 254) a saber: "Como sin lenguaje no sólo no se puede pensar ninguna conciencia filosófica, sino ni siquiera humana, no es la conciencia la que ha presidido la formación del lenguaje; y sin embargo, cuanto más profundamente penetramos en él, tanto más rotundamente se descubre que su profundidad supera con mucho la de la creación más consciente. Con el lenguaje ocurre como con los seres orgánicos; creemos verlos formarse ciegamente, y no podemos contravenir la insondable intencionalidad que rige su formación hasta en sus más mínimos detalles" (Nietzsche, 2013: 811).

9 De ahí la importancia de distinguir heurísticamente, como señala Sánchez Meca en su introducción a los Escritos filológicos, "entre la retórica como aplicación persuasiva del lenguaje en las técnicas tradicionales de la oratoria y la elocuencia, y la retórica como clave para entender la naturaleza y esencia del lenguaje" (Nietzsche, 2013: 65).
} 
sensaciones en palabras y conceptos; cuarto: que el hombre es siempre, por tanto, un sujeto artístico, puro creador de metáforas, que sin embargo ha olvidado la verdadera naturaleza metafórica del lenguaje, a fin de habilitar la comunicación entre los demás seres humanos, sellar el pacto social y garantizar con ello su propia supervivencia.

Merece la pena detenerse un momento y apreciar el salto cualitativo que adquiere ahora la reflexión sobre el lenguaje frente a lo que se había afirmado, apenas un año antes, en El nacimiento de la tragedia. En aquella obra, la extrema dependencia con respecto a la metafísica schopenhaueriana -pensemos, por ejemplo, en el capítulo 16- había desembocado, entre otras cosas, en una necesaria integración de su concepción redentora de la música como liberación del yo de los estrechos límites de la individuación y del sufrimiento inherente a toda existencia. En la medida en que Nietzsche la identificaba con el arte dionisíaco, núcleo y origen simultáneos de la experiencia trágica, la música se convertía en el verdadero lenguaje universal, independiente del mundo fenoménico. La música era el lenguaje inmediato de la voluntad, porque no era el reflejo de la apariencia, reproducción del fenómeno, sino la representación inmediata del dolor y el conflicto de la voluntad como esencia última del mundo. Es decir, "representa, con respecto a todo lo físico del mundo, lo metafísico, y con respecto a todo fenómeno, la cosa en sí" (Nietzsche, 2011: 400). Al tiempo que reevaluaba románticamente la posibilidad de recurrir a la poesía, al mito y al símbolo -también de reefectuarlos en el presente a través de la música wagneriana-, esta concepción "melocéntrica" (Llinares, 1996: 241) devaluaba, a su vez, el lugar de los conceptos y las palabras, el alcance del pensamiento conceptual y el lenguaje verbal, pertenecientes todos ellos al arte apolíneo, junto con las artes plásticas y figurativas. Incapaces de alcanzar el simbolismo universal de la música -entendida en todo momento como simbolismo de las pulsiones (Symbolik der Triebe)-, incapaces de expresar la contradicción y el dolor primordiales, su lugar era secundario, sus cualidades, imperfectas y derivadas ${ }^{10}$.

Ahora, sin embargo, si el arte ya no se asocia con la inmediatez dionisíaca de la música; si el lenguaje, a su vez, es reevaluado como ejercicio de inconscientes

10 Sin duda un argumento troncal en Schopenhauer, asumido modélicamente por Wagner en su fundamentación teórica de su Beethoven en 1870/71: "Las palabras son y permanecen para la música un añadido extraño que tiene un valor secundario, puesto que el efecto del tono es más poderoso, infalible y rápido que el de las palabras: si éstas se incorporan a la música deben por eso ocupar sólo un lugar completamente subordinado y someterse a ella" (Schopenhauer, 2009: 320; Wagner, 2016: 78-81). 
actividades artísticas puramente retóricas, la metafísica schopenhaueriana difícilmente podía ofrecer el suelo adecuado para describir la producción de formas y de apariencias por parte del sujeto artístico, ni explicar satisfactoriamente los complejos mecanismos de la génesis de nuestras representaciones desde una comprensión no romántica. La consecuencia, por tanto, es irreversible, sobre todo en lo que respecta a la legitimación teórica del proyecto wagneriano, cuya base filosófica la ofrecía una forzada interpretación romántico-idealista, en términos claramente dialécticos, de la metafísica de Schopenhauer. Quizá por eso -o precisamente por eso -, los escritos póstumos velan un sentir nietzscheano que quiso mantener en secreto, como el expresado en el importante fragmento 19 [143]: "La música como suplemento del lenguaje: muchos estímulos y estados de total excitación, que no puede representar el lenguaje, los reproduce la música" (Nietzsche, 2010: 355).

Con todo, la acreditada importancia del cuaderno 19 de los Fragmentos Póstumos no sólo radica en el hecho de ilustrar cómo la asimilación de las tesis centrales de Gerber habilita un espacio de reflexión filosófico para verificar, esta vez a través del lenguaje, los procesos que conducen a la constitución del mundo como representación, de mostrar, asimismo, cómo en la propia estructura del lenguaje encontramos el origen de las categorías metafísicas fundamentales. A mi modo de ver, este cuaderno supone un verdadero punto de inflexión en el pensamiento del joven Nietzsche, porque la erkenntnistheoretische Position que se va fijando paulatinamente en esos apuntes y que desemboca, en última instancia, en el escrito Sobre verdad y mentira en sentido extramoral, se nutre al mismo tiempo de la integración teórica de otros espacios de reflexión de la filosofía y de las ciencias naturales. En un acto creativo típicamente nietzscheano, la reflexión acerca del origen del lenguaje, limitada en un principio al curso de retórica, explota simultáneamente en varias direcciones de trabajo, siempre abiertas y provisionales; experimenta con otros accesos subterráneos al problema de la verdad como mentira, al problema también de su transmisión y transferencia, de su valor y estatus cognoscitivos, de su adecuación o no a la realidad desde una lectura crítica de toda empresa de conceptualización, desde un posicionamiento radicalmente escéptico frente a todo columbarium conceptual.

Para hacerle justicia a esta ganancia de complejidad, y aun a riesgo de quedarnos en la superficie, señalaremos rápidamente a otros dos autores importantes, Karl Friedrich Zöllner y Afrikan Spir, cuya asimilación creativa por parte del 
joven filósofo posibilitan, junto a Gerber, la síntesis creativa propiamente dicha de Sobre verdad y mentira en sentido extramoral.

\subsection{Zöllner y Spir}

“¿Has oído algo del escándalo de Zöllner en Leipzig? Lee su libro sobre la naturaleza de los cometas. Es para quedarse estupefacto por la cantidad de cosas que hay en él para nosotros" (Nietzsche, 2007: 355). Con estas palabras, escritas a su amigo Rohde a mediados de noviembre de 1872, encontramos una de las pistas más sugerentes para rastrear la lectura que el joven profesor acababa de realizar de Über die Natur der Cometen (Crescenzi, 1994: 419). En efecto, el entonces catedrático de astrofísica en Leipzig había sido atacado por sus propios colegas universitarios, algo que a Nietzsche, siempre atento a los debates científicos, llamó y mucho la atención, sobre todo tratándose de su antigua universidad $^{11}$. Ha sido el indiscutible mérito de Andrea Orsucci (1994: 197-200) haber demostrado hasta qué punto la teoría zöllneriana de las "inferencias inconscientes” (unbewusste Schlüsse), según la cual la elaboración intuitiva de nuestras percepciones es el resultado de una operación intelectual inconsciente que aprende, mediante razonamientos analógicos (Analogieschlüsse), a anticipar los efectos de una causa, bebe no sólo de los avances experimentales en el ámbito de la electrodinámica (W.E. Weber) y sobre todo de la óptica fisiológica (Helmholtz), sino también de las intuiciones epistemológicas del joven Schopenhauer alentadas por su admiración hacia la teoría de los colores goetheana. Pues precisamente la combinación zöllneriana de ambas direcciones posibilita la idea, asumida por Nietzsche, de que los razonamientos analógicos, al fundamentarse siempre en sensaciones de placer o displacer (Zöllner, 1872: 201-203, 361-364), permiten extender la anticipación intelectual de los efectos, como momento constitutivo pero inconsciente de la elaboración del material de nuestro conocimiento, a todas las exteriorizaciones humanas más allá de lo estrictamente fisiológico:

11 A quienes dedica palabras no exentas de dureza: "Este hombre leal, después de aparecer su libro, ¡ha sido prácticamente excomulgado de la manera más innoble por toda la república de los eruditos, sus amigos más íntimos han renegado de él, y a lo largo y a lo ancho han difundido la noticia de que está 'loco'? En serio, ¡se le considera un 'enfermo mental' porque no toca la misma música que la banda de sus colegas! ¡Éste es el espíritu de la oclocracia intelectual de Leipzig!" (Nietzsche, 2007: 355). Al poco, Nietzsche saldrá públicamente en su defensa a través de su artículo prowagneriano "Un mensaje de año nuevo al editor del semanario En el nuevo Reich" (Nietzsche, 2011: 489). 
El hombre exige la verdad y la produce en las relaciones morales con los hombres, en eso se basa toda vida en común. Se anticipan las graves consecuencias de las mentiras recíprocas. De aquí procede el deber de la verdad. $\mathrm{Al}$ narrador épico se le permite la mentira, porque en este caso no se prevé ningún efecto dańino. Por consiguiente, se permite la mentira cuando se considera como algo agradable: la belleza y el encanto de la mentira, presupone que ella no produzca daño (Nietzsche, 2010: 346).

En otras palabras, el salto de la esfera estrictamente científica a la esfera moral habilita, a ojos de Nietzsche, la combinación de las ideas de Zöllner con los motivos gerberianos. En cierto modo, asume el modelo o paradigma que describe la primera esfera y lo aplica a otra esfera del conocimiento distinta, para introducir la hipótesis de que la metáfora tiene un valor eminentemente epistemológico, por cuanto permite entender el conocimiento como el resultado de una "transposición” (Übertragung) metafórica. Pues también la constitución del lenguaje representativo puede ahora retrotraerse hasta una operación inconsciente en que se traducen, trasponen, transfieren -porque se anticipan intelectualmente- una serie de aprehensiones subjetivas que queremos ver reinterpretadas como causas, cuando, en realidad, no son sino efectos que hemos olvidado que lo son. No es otra la definición de metonimia, aunque es extensible también a todo el proceso de metaforización, como bien atestigua este decisivo fragmento preparatorio: "Todas las figuras retóricas (es decir, la esencia del lenguaje) son inferencias lógicas falsas. ¡Con ellas comienza la razón!” (Nietzsche, 2010: 368).

Con esta última cita llegamos, de hecho, al segundo de los autores que me interesa destacar en esta creativa línea de investigación de Nietzsche, pues con la lectura que hace del filósofo ucraniano Afrikan Spir -cuya asimilación parcial, en dos pasos claramente delimitados ${ }^{12}$, ha sido mostrada con solvencia por D'Iorio (1993, 257-258)-, la reflexión gnoseológica alrededor del origen del lenguaje

\footnotetext{
${ }^{12}$ En un primer momento, Nietzsche elaborará algunas ideas de Forschung nach der Gewissheit in der Erkenntnis der Wirklichkeit (Spir, 1869), de donde extrae sobre todo el impulso crítico respecto de los juicios sintéticos kantianos y su problemático valor cognoscitivo. En un segundo momento, coincidiendo con la preparación de los materiales sobre Parménides para La filosofía trágica en la época de las griegos, el joven profesor tomará prestada en marzo de 1873 su obra principal, Denken und Wirklichkeit. Versuch einer Erneuerung der kritischen Philosophie (Spir, 1873). La confrontación con Spir es siempre compleja, aunque en este primer contacto podamos señalar el objeto principal de discusión, a saber: la función del principio de identidad, que para el filósofo ucraniano no sólo viene a ser un principio lógico y analítico, sino también un principio sintético que hace las veces de discriminante ontológico.
} 
adquiere nuevos argumentos decisivos. En primer lugar, a Nietzsche le interesa su idea de que los juicios sintéticos, en los cuales la filosofía crítica de Kant y de sus seguidores habían consolidado la fuente del conocimiento de la realidad empírica (Wirklichkeit), tengan una validez cognoscitiva nula. A partir de la unión ilógica de lo que es intrínsecamente no idéntico, Spir deduce el carácter ilusorio del mundo fenomenal. Nietzsche coincide con Spir en lo tocante a esta falta de validez cognoscitiva, pero a diferencia del filósofo ucraniano aborda este tópico de la filosofía kantiana desde el impulso gerberiano, a fin de demostrar el carácter relacional de las cualidades expresadas en dichos juicios, cualidades entendidas no desde un punto esencialista, sino estrictamente nominalista. Los juicios sintéticos revelan, en otras palabras, la naturaleza retórica e ilógica de la estructura del lenguaje. En el fondo, pues, dichos juicios serían, al decir de D'Iorio, "un cas particulier de métonymie dans laquelle l'essence et les effets d'un chose sont confondus" (D’Iorio, 1993: 260) ${ }^{13}$.

En segundo lugar, Nietzsche reelabora la idea de Spir según la cual no puede darse certeza absoluta más que en las tautologías, expresión directa del principio de identidad. Pero a diferencia del filósofo neokantiano, no reconoce a este principio más valor que el de ser, como todas las verdades universales y a priori, el resultado arbitrario de una génesis artística ilógica. No tiene validez de criterio ontológico. "El conocimiento", escribirá en el fragmento 19 [236], "considerado en sentido estricto, sólo tiene la forma de la tautología y está vacío. Todo conocimiento que nos estimula es una identificación de lo noidéntico, de lo semejante, es decir, es esencialmente ilógico" (Nietzsche, 2010: 373). Basta con lanzar una rápida mirada a Sobre verdad y mentira en sentido

\footnotetext{
${ }^{13}$ Ello es así porque Spir no juzga la realidad del mundo a partir de su conformidad con leyes lógicas como el principio de identidad, sino que juzga las leyes lógicas a partir de la realidad (ilógica) del mundo y las declara inadecuadas para procurarnos un conocimiento verdadero de aquél. Nietzsche se hace eco de esta idea en siguiente fragmento 19 [242], identificado por D’Iorio (1993: 261) como una transcripción de Spir: "La esencia de la definición: el lápiz es un cuerpo alargado, etc. $A$ es $B$. Eso que es largo también está coloreado. Las cualidades contienen sólo relaciones. Un cuerpo determinado equivale a un cierto número de relaciones. Las relaciones nunca pueden ser la esencia, sino sólo consecuencias de la esencia. El juicio sintético describe una cosa según sus consecuencias, es decir, esencia y consecuencias se identifican, es decir, una metonimia. Por lo tanto, el juicio sintético incluye en su esencia una metonimia, es decir, es una falsa ecuación. Es decir, los raciocinios sintéticos son ilógicos. Cuando nosotros los aplicamos, estamos presuponiendo la metafísica popular, es decir, la que considera efectos como causas. El concepto 'lápiz' se confunde con la 'cosa' lápiz. El 'es' del juicio sintético es falso, contiene una transposición, se yuxtaponen dos esferas diferentes entre las cuales nunca puede tener lugar una ecuación. Vivimos y pensamos bajo puros efectos de lo ilógico, en el no saber y en el saber erróneo" (Nietzsche, 2010: 374).
} 
extramoral para confirmar el sedimento de algunas de estas ideas: "La génesis del lenguaje no se da de una manera lógica" (Nietzsche, 2011: 612), aunque el pasaje clave es el siguiente:

Sólo mediante el olvido puede el ser humano llegar a figurarse alguna vez: que esté en posesión de una verdad en el grado que acabamos de señalar. Si no está dispuesto a contentarse con la verdad en forma de tautología, es decir, con conchas vacías, entonces estará perpetuamente trocando ilusiones por verdades (Nietzsche, 2011: 611)

Sirvan estas breves pinceladas sobre la influencia de Zöllner y Spir para acabar de completar el cuadro sinóptico que subyace a Sobre verdad y mentira en sentido extramoral. Anudados todos los cabos desde la asunción del esquema genético gerberiano, exploremos, en un último movimiento, más sintético, el destilado final de la búsqueda y experimentación del joven Nietzsche en materia de preocupaciones gnoseológicas, en el que se dan encuentro todas las líneas de fuerza que hemos venido desarrollando hasta el momento.

\subsection{La transferencia de la verdad - la verdad como proceso fisiológico}

La tesis fuerte de Nietzsche es que el lenguaje debe retrotraerse a una operación cognitiva, de naturaleza inconsciente, por la que no sólo se ha constituido todo lenguaje, sino por la que se ha olvidado el carácter fisiológico de la verdad y la mentira. "La verdad y la mentira son algo fisiológico", afirma categóricamente en el fragmento 19 [102] (Nietzsche, 2010: 347). Por tanto, es necesario explicitar el proceso psicofisiológico de transferencia (Übertragung) que conduce a dicho olvido. Para Nietzsche la secuencia, que modifica ligeramente la secuencia gerberiana, es la siguiente: en primer lugar, se halla siempre una excitación nerviosa (Nervenreiz), que es la que configura una primera imagen percibida. O dicho de un modo más preciso: determinadas sensaciones o estímulos corporales de placer o displacer producen determinadas imágenes en el individuo, y este, a su vez, les atribuye una primera forma primordial $(U r f o r m)^{14}$. El estímulo es, pues,

${ }_{14}$ Como explica en el fragmento preparatorio 19 [84], "el verdadero material de todo conocimiento está constituido por las más delicadas sensaciones de placer y de displacer: el verdadero secreto se encuentra en aquella superficie en la que la actividad nerviosa, consistente en 
el presupuesto de toda intuición. En segundo lugar, dichas imágenes se traducen a ciertos sonidos o formas expresivas sonoras, esto es, a palabras. "¿Qué es una palabra?" se pregunta, "la reproducción en sonidos articulados de un estímulo nervioso" (Nietzsche, 2011: 611). Y en tercer y último lugar, llegamos a la formación de conceptos genéricos, comunes y comunicables mediante la fuerza artística y creadora del olvido, es decir, aquella fuerza que imita, asimila lo ajeno, excluye su singularidad e iguala lo que es intrínsecamente desigual, que en cierto modo es siempre injusta, y que sobre todo acaba conformándose como un lenguaje conceptual estructurado por desplazamientos significativos y productores de sentido colectivo. En palabras de Nietzsche:

Toda palabra se convierte de manera inmediata en concepto cuando deja de servirle a la vivencia originaria gracias a la cual se generó, por ejemplo, como recuerdo, y tiene que pasar a adaptarse a innumerables vivencias más o menos similares, esto es, hablando con rigor, nunca idénticas: es decir, tiene que valer al mismo tiempo para casos claramente diferentes. Todo concepto se genera igualando lo no-igual (Nietzsche, 2011: 612).

Primera conclusión: al plantear este origen del lenguaje de naturaleza inconsciente y su condición de posibilidad en el olvido humano; al desmontar, por otro lado, los procedimientos operativos de la lógica aplicando las figuras de la retórica clásica a la configuración del lenguaje representativo y la teoría metafísica del conocimiento, no sólo se está planteando la ruptura con la comprensión metafísica de la verdad como correspondencia entre pensamiento y realidad en sí, como adecuación entre concepto y realidad, sino también una radicalización de las distintas problemáticas, prefiguradas ya en los ańos formativos en Leipzig, sobre la consistencia teórica y el valor del conocimiento desde una lectura crítica del proyecto kantiano y schopenhaueriano ${ }^{15}$. El valor del conocimiento no puede estribar ya en ninguna relación con una instancia exterior a la esfera del propio

placer y en dolor, señala formas: aquello que es una sensación proyecta al mismo tiempo formas, que luego vuelven a producir nuevas sensaciones" (Nietzsche, 2010: 344).

15 Este punto es importante: mientras que, para Kant, el conocimiento del fenómeno es objetivo porque tiene la forma que le impone el entendimiento, esto es, habría una necesidad trascendental en la forma de los objetos, para Nietzsche la forma de los objetos ya no puede revelar ningún carácter universal ni necesario. No serán sino las sensaciones las que a partir de ahora produzcan las formas de nuestro entendimiento, mientras que "la palabra fenómeno encierra muchas seducciones, por lo que hago todo lo posible para evitarla: porque no es cierto que la esencia de las cosas se manifieste en el mundo empírico" (Nietzsche, 2011: 615). 
ser viviente en que se originan, más bién la atención debe dirigirse a dilucidar a qué necesidades nuestras están supeditadas su surgimiento y su conservación. En este sentido, el intelecto humano aparece condicionado por entero por la "organización psicofísica" (Lange) y sometido, como todos los demás aspectos de la vida de los organismos, a la azarosidad implícita en las universales condiciones de supervivencia y adaptación darwinianas. En este sentido, pues, la irrupción teórica de la dimensión fisiológica y, por tanto, la reevaluación de la vida y el cuerpo como categorías de conocimiento de la Modernidad, revelan el carácter ineludible de lo que Aspiunza ha descrito recientemente como "facticidad de nuestra organización psicofísica" ${ }^{16}$. Desde este nuevo horizonte de comprensión, la concepción tradicional de la verdad, esto es, la noción metafísica de verdad, tiene poco o nada que decir: ya no es, como se afirmaba en El nacimiento de la tragedia, esa correspondencia metafísica con el ser, sino una pura y nuda convención, mejor aún, una pura ficción o ilusión o mentira necesarias, producidas como instrumento de dominio al servicio de la vida. Es decir, lo que queda es una verdad como error útil, cuya evidente dimensión pragmática, como ha señalado también Aspiunza (2012: 21), “considerada en su carácter relativo deja de ser tal error; es más, es un comportamiento que suele resultar imprescindible para seguir viviendo. [...] Lo de 'útil' viene a ser, por lo tanto, una manera de señalar el carácter derivado o relativo de las verdades en que vivimos: no descubrimientos de la realidad, sino producciones, excreciones de un cuerpo".

Segunda conclusión: si las sensaciones son, para el joven Nietzsche, las que originariamente producen las formas de nuestro entendimiento, la causalidad científica planteada en los términos tradicionales se revelaría como una más de las numerosas construcciones antropomórficas que estructuran lingüísticamente nuestra realidad, ratificando con ello las tempranas intuiciones gnoseológicas de la época de Leipzig. Nietzsche es categórico en este punto: "Hay que demostrar que todas las construcciones del mundo son antropomorfismos" (Nietzsche, 2010: 351). A la vista de la imposibilidad de afirmar una representación y una percepción verdaderas de los objetos del mundo, la relación del animal humano con el mundo ya no podrá tener una base epistemológica ni cognitiva, sino eminentemente estética: "Las transformaciones químicas en la naturaleza inorgánica son quizá también procesos artísticos, roles miméticos, que una fuerza

16 "No podemos ir más allá de la facticidad de nuestra organización psicofísica, puesto que dependemos de nuestros sentidos, de nuestro cuerpo. Dicho de modo más claro: de la realidad nos llega solo lo que nuestros sentidos perciben, es decir, nos llega la realidad en cuanto visible, audible, táctil, etc., no la realidad en sî” (Aspiunza, 2012: 16). 
interpreta: ipero hay muchos! que ella puede interpretar" (Nietzsche, 2010: 337). Por consiguiente, necesitamos en todo momento el arte para vivir, sí, pero no ya en un sentido metafísico, sino en cuanto modelo o paradigma para entender cómo la producción de formas culturales del ser humano no radica nunca en su capacidad de conocer y comprender las cosas o la verdad, sino en su valentía a la hora crear y sentir placer en ello, esto es, de imitar olvidando, omitiendo, desechando y siendo constitutivamente injusto.

\section{Bibliografía}

Aspiunza, Jaime (2012). "Nietzsche, el lenguaje y la verdad: algunas precisiones actuales". Estudios Nietzsche 12, pp. 13-24.

Barbera, Sandro (1995). "Eine Quelle der frühen Schopenhauer-Kritik Nietzsches: Rudolf Hayms Aufsatz 'Arthur Schopenhauer'. Nietzsche-Studien 24, pp. 124- 136.

Behler, Ernst (1994). "Die Sprachtheorie des frühen Nietzsche”. 'Centauren-Geburten'. Wissenschaft, Kunst und Philosophie beim jungen Nietzsche. Berlin/New York: Walter de Gruyter, pp. 100-111.

Borsche, Tilman (1994). "Natur-Sprache. Herder - Humboldt - Nietzsche". 'Centauren-Geburten'. Wissenschaft, Kunst und Philosophie beim jungen Nietzsche. Berlin/ New York: Walter de Gruyter, pp. 112-130.

Broese, Konstantin (2005). "Nietzsches frühe Auseinandersetzung mit Kants Kritizismus". Kant und Nietzsche im Widerstreit. Berlin/New York: Walter de Gruyter, pp. 363-371.

Crawford, Claudia (1988). The Beginnings of Nietzsche's Theory of Language. Berlin. Walter de Gruyter.

CrescenZi, Luca (1994). "Verzeichnis der von Nietzsche aus der Universitätsbibliothek in Basel entliehenen Bücher (1869-1879)". Nietzsche-Studien 23, pp. 388-442.

D’Iorio, Paolo (1993). "La superstition des philosophes critiques". Nietzsche-Studien 22, pp. 257-294.

De Man, Paul (1990). Alegorias de la lectura. Lenguaje figurado en Rousseau, Nietzsche, Rilke y Proust. Barcelona: Lumen [ed. original (1979): Allegories of Reading. Figural Language in Rousseau, Nietzsche, Rilke, and Proust. New Haven/London: Yale UP].

Fischer, Kuno (1860). Geschichte der neueren Philosophie, vols. 3 y $4=$ Immanuel Kant. Entwicklungsgeschichte und System der kritischen Philosophie. Vol. 1: Entstehung und Begründung der kritischen Philosophie. Die Kritik der reinen Vernunft. Vol. 2: Das Lehrgebäude der kritischen Philosophie. Das System der reinen Vernunft. Mannheim: Bassermann \& Mathy. 
Gentili, Carlo (2010). "Kants 'kindischer” Anthropomorphismus. Nietzsches Kritik der 'objektiven' Teleologie”. Nietzsche-Studien 39, pp. 100-119.

Gerratana, Federico (1988). "Der Wahn jenseits des Menschen. Zur frühen E. v. Hartmann-Rezeption Nietzsches (1869-1874)”. Nietzsche-Studien 17, pp. 391433.

Goethe, Johann Wolfgang (1997). Teoría de la naturaleza. Estudio preliminar, traducción y notas de Diego Sánchez Meca. Madrid: Tecnos.

von Hartmann, Eduard (1869). Philosophie des Unbewussten. Berlin: Duncker.

Hill, Kevin R. (2003). Nietzsche's Critiques. The Kantian Foundations of his Thought. Oxford: Clarendon Press.

Kofman, Sarah (1971). “Nietzsche et la métaphore”. Poétique 5, pp. 77-98.

Lacoue-Labarthe, Philippe (1971). “Le détour (Nietzsche et la réthorique)”. Poétique 5, pp. 53-76.

Lange, Friedrich Albert (1866). Geschichte des Materialismus und Kritik seiner Bedeutung in der Gegenwart. Iserlohn: Baedecker.

Lavernia, Kilian (2017). “Texturas goetheanas en el joven Nietzsche: apuntes sobre las funciones del Fausto en El nacimiento de la tragedia. Estudios Nietzsche 17 [en prensa].

Llinares, Joan B. (1996). "La filosofía del lenguaje en Nietzsche". Metafísica y pensamiento actual. Conocer a Nietzsche. Salamanca: Sociedad Castellano-Leonesa de Filosofía, pp. 237-258.

Meijers, Anthonie (1988). “Gustav Gerber und Friedrich Nietzsche”. Nietzsche-Studien 17, pp. 369-390.

Meijers, Anthonie/Martin Stingelin (1988). "Konkordanz zu den wörtlichen Abschriften und Übernahmen von Beispielen und Zitaten aus Gustav Gerber: Die Sprache als Kunst (Bromberg 1871) in Nietzsches Rhetorik-Vorlesung und in 'Ueber Wahrheit und Lüge im aussermoralischen Sinne' ”. Nietzsche-Studien 17, pp. 350-368.

Nancy, Jean-Luc (1973). "La thèse de Nietzsche sur la Téléologie". Nietzsche aujourd'hui I. Paris: UGE, pp. 57-80.

Nietzsche, Friedrich

- (2005). Correspondencia I. Junio 1850 - Abril 1869. Traducción, notas y apéndices de Luis E. de Santiago Guervós. Madrid: Trotta.

- (2007). Correspondencia II. Abril 1869 - Diciembre 1874. Traducción y notas a las cartas de José Manuel Romero Cuevas y Marco Parmeggiani. Introducción y apéndices de Marco Parmeggiani. Madrid: Trotta. 
- (2010). Fragmentos póstumos. Volumen I (1869-1874). Edición dirigida por Diego Sánchez Meca. Traducción, introducción y notas de Luis E. de Santiago Guervós, $2^{a}$ edición corregida y aumentada. Madrid: Tecnos.

- (2011). Obras completas I: Escritos de juventud. Edición dirigida por Diego Sánchez Meca. Traducción, introducciones y notas de Joan B. Llinares, Diego Sánchez Meca y Luis E. de Santiago Guervós. Madrid: Tecnos.

- (2013). Obras completas II: Escritos filológicos. Edición dirigida por Diego Sánchez Meca, traducción, introducciones y notas de Manuel Barrios, Alejandro Martín, Diego Sánchez Meca, Luis E. de Santiago Guervós y Juan Luis Vermal. Madrid: Tecnos.

Orsucci, Andrea (1994). "Unbewusste Schlüsse, Anticipationen, Übertragungen. Über Nietzsches Verhältnis zu Karl Friedrich Zöllner und Gustav Gerber”. 'Centauren-Geburten'. Wissenschaft, Kunst und Philosophie beim jungen Nietzsche. Berlin/ New York: Walter de Gruyter, pp. 193-207.

Porter, James I. (2000). Nietzsche and the Philology of the Future. Stanford: Stanford University Press.

Salaquarda, Jörg (1978). "Nietzsche und Lange". Nietzsche-Studien 7, pp. 236-260.

Schopenhauer, Arthur (2004). El mundo como voluntad y representación I. Traducción, introducción y notas de Pilar López de Santamaría. Madrid: Trotta.

Spir, Afrikan (1869). Forschung nach der Gewissheit der Erkenntniss der Wirklichkeit. Leipzig: Förster \& Findel.

- (1873). Denken und Wirklichkeit. Versuch einer Erneuerung der kritischen Philosophie, 2 vols. Leipzig: Findel.

Stack, George (1991). "Kant, Lange, and Nietzsche. Critique of Knowledge". Nietzsche and Modern German Thought. London/New York: Routledge, pp. 30-58.

- (1983). Lange and Nietzsche. Berlin/New York: Walter de Gruyter.

Vaininger, Hans (1911). Die Philosophie des Als Ob. System der theoretischen, praktischen und religiösen Fiktionen der Menschheit auf Grund eines idealistischen Positivismus. Mit einem Anhang über Kant und Nietzsche. Leipzig: F. Meiner.

Wagner, Richard (2016). Beethoven. Edición de Blas Matamoro. Madrid, Fórcola.

Zöllner, Karl Friedrich (1872). Über die Natur der Cometen. Beiträge zur Geschichte und Theorie der Erkenntniss. Leipzig: Engelmann. 
Recibido: 11/09/2015

Aceptado: 28/09/2015

\section{(2) $0(90$}

ENDOXA está bajo una licencia de Creative Commons Reconocimiento-NoComercial-SinObraDerivada 4.0 Internacional 
